the complete band-spectrum (at a pressure of about 5 -10 $\mathrm{mm}$.) in which the variability of the spectrum is most conspicuous, viz., in the green and blue (from wave-lengths 562 to 449); this is followed by an account of the gradual changes taking place in two different places when the density of the gas is decreased. It would lead us too far to enter into the details here; suffice it to say that the richly-shaded band-spectrum changes quite gradually into a line-spectrum, and that most of the lines of the latter are in places which show no maximum of brightness in the band-spectrum. It results from these observations that the positions of the maxima of emission-power do not remain at all the same in all temperatures, but that in consequence of the changes of temperature accompanying the decrease of pressure they may be considerably displaced.

Prof. Wiillner gives the reasons why the wider tubes are unsuitable for the gradual conversion of band-spectrum into linespectrum, and eventually describes the differences between the line-spectrum obtained from the band-spectrum in the manner described, and the line-spectrum obtained by the spark. Upon comparison of those regions in the two spectra which were examined more closely (beginning at wave-length 572 ), it was found that in the spark-spectrum there are about forty lines in this region. Of these eight correspond very closely to maxima or lines in the fully developed band-spectrum. The number of coincidences with the lines of the low density line spectrum is, however, much greater; perfect, or very nearly perfect coin. cidence occurs in nineteen lines, i.e., about half the number, and amongst these there are four which are the same in the three different forms of the nitrogen spectrumo. The brightest lines of both line-spectra are, indeed, perfectly coincident. These are the yellowish-green lines 568,4 and $567, \mathrm{r}$, the green lines 500.7 and $500^{\circ} 4$ (which result from the green-channelling described in detail) and the blue line $463^{\circ} 2$ (developed from the blue channelling). Another interesting similarity exists between the two line-spectra, however differently about half of their lines may be situated.

Pliicker and Hittorf distinguish five principal groups in the line-spectrum of nitrogen, between which there are other single lines. Of these five groups Nos. II. to V. belong to the region specially studied by Prof. Wuillner. These groups are :Group II. between wave-lengths $577-567$

Group III. , , ,

Between groups III. and IV. there are first three lines: $535^{\circ} 6$, $534^{\circ} 4$, and $53^{\prime} \cdot 3$; and then two lines : $5^{18^{\prime}} 1$, and $5^{1} 7^{\circ} 6$.

Group IV, between wave-lengths 508-499

Between groups IV. and V. there are first four lines: from $489^{\circ} 6$, to $484^{\circ} 8$, and further on three lines: $4^{8} 0^{\circ} 5,479^{\circ} \mathrm{o}$, and $478 \cdot \mathrm{I}$.

Group V. between wave-lengths $464^{\circ} 5-460^{\circ} 2$.

All these groups are situated in such parts of the spectrum where also the line-spectrum developed from the band-spectrum is very rich in lines. It follows, therefore, that the spark-line spectrum is developed, on the whole, in such places which show the greatest variability, even in a gradual decrease of the density of the gas, and which are richest in lines in the low-density line. spectrum.

Prof. Wiillner recapitulates his interesting treatise in the following manner:-The course of spectral plaenomena of nitrogen, which takes place when the gas is gradually reduced in density in tubes of sufficientiy small diaweter, shows exactly those changes which may be deduced from Kirchhoff's maxim, that the smaller the number of incandescent molecules, the more the spectrum contracts into a number of bright lines.

At the same time it may be directly observed when the density of the gas is decreasing, how, in consequence of the temperature rising throngh increasing resistance in the tube, the maxima of brightness change their position, how the maxima of the fullydeveloped band-spectrum fade away, and how the lines become prominent in places which are either secondary or tertiary maxima or uniformly illuminated regions in channelled spaces. Now, if we further consider that the lines of the spark-spectrum, compared to those of the former line-spectrum, are not more considerably displaced than the latter are with regard to the maxima of the band-spectrum, then we can hardly doubt that in the different forms of the nitrogen-spectrum we see nothing else but the light emitted each time in accordance with the different temperature, density, and thickness of the radiating layer of gas, and that a new hypothesis for the explanation of these spectral phenomena is unnecessary and superffuous.

\section{A HISTORICAL SKETCH OF THE VARIOUS VAPOUR-DENSITY METHODS ${ }^{1}$}

A LTHOUGH Southern, ${ }^{2}$ in $x 803$, made some very careful experiments to determine how much water was required to furnish I cubic foot of steam at various pressures, still the foundation of vapour-density methods was laid by Gay-Lussac.

$\mathrm{He}$, in $18 \mathrm{II},{ }^{3}$ started on the correct basis of accurate work when he heated a weighed quantity of substance over mercury in a graduated vessel. Muncke, in $1816,{ }^{4}$ heated the substances in vacuo in elliptic glass balloons of $\mathrm{r}_{55} \mathrm{c}$. i. capacity, closed with a stop-cock and with thermometer and syphon barometer suspended inside. In $\mathrm{I}_{222^{5}}$ Cagniard de la Tour determined the combined effects of heat and pressure on certain volatile liquids, but as his results were on the question of maximum vapour-density, they hardly enter the domain of the present sketch. In the same year Despretz, ${ }^{6}$ who gave no drawing, and only a very imperfect description of his apparatus, published a method in which he used a 9-litre exhausted globe, and made his determinations at atmospheric temperatures, employing only a small quantity of substance.

In 1826 Dumas, ${ }^{7}$ wishing to operate on substances which attack mercury, worked out and published his well-known method in which the volume is definite, but the amount of substance required to fill that volume with vapour has to be subsequently determined.

In $1833^{8}$ Mitscherlich proposed using tubes, sealed at one end and drawn to a neck at the other, instead of bulbs, and gave details and drawings of the apparatus for heating them; but Dumas, two years later, objected to the proposed alteration in his method, for he wrote :-

"We must then leave to this operation all its simplicity to make it essentially practical, and such, in fact, that with an ordinary cast-iron pot and some pieces of iron wire we can per: form it. This is what I have done from the first, and what $I$ persist in doing, my aim never having been to make a piece of apparatus for the cupboard of the physicist, but to give chemists a simple and eminently practical and yet exact process. After all they are the only ones to be considered." 9

Deville and Troost, ${ }^{10}$ however, in 1860 , in referring to that same apparatus, called it "La méthode si élégante de M. Mitscherlich."

Bineau, in 1838 ,i1 published an elaborate paper, but unfortunately without any drawings, for when we read the following paragraph, "The bodies on which I have worked have been volatilised sometimes by the aid of heat by following the pro. cess of Dumas or that of Gay-Lussac, sometimes without elevation of temperature by working in the barometric vacuum or by allowing the vaporisation to take place in dry air or hydrogen," we cannot but feel that an enormous amount of valuable work has been lost for want of details. In 1844 we find Cahours, 12 as well as Bineau, ${ }^{13}$ at work at the same subject. In 1846 the latter ${ }^{14}$ repeated the experiments of Despretz with slight modifications, but called attention to the fact that the result was seriously affected by very small errors in reading off the mercurial column.

In 1849 Regnanlt ${ }^{15}$ described an apparatus very similar to that of Mitscherlich, but arranged the tube supports so that the two could be withdrawn simultaneously; he also dispensed with sealing the tube containing air by providing it with a stop-cock. Binean, 16 in 1859 , in order to operate at high temperatures, coated the glass tubes with clay and heated them in a sand-bath.

Regnault, ${ }^{17}$ in 186 I, to obtain the same result, used iron tubes, and to ensure uniformity of temperature, heated them in a castiron " tube which was made to revolve over gas-burners. The tube which served as air-thermometer was furnished with a stop. cock, but that containing the substance only terminated in a small aperture, and was not closed, as a sufficient quantity was

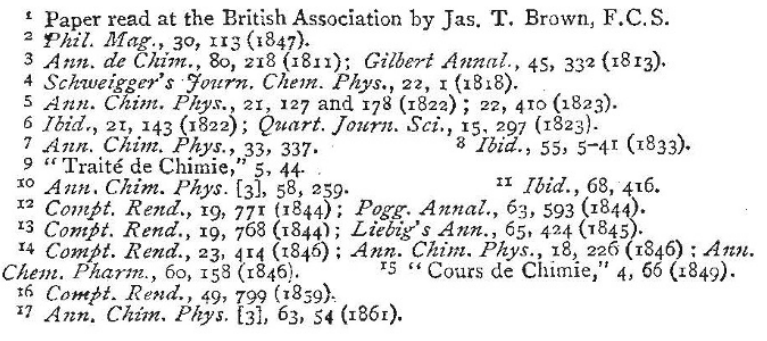

I7 Ann. Chim. Phys. [3], 63, 54 (186r). 
introduced before the heating, to allow it to be taken for granted that during the experiment there was no residual air. ${ }^{1}$ Another method of Regnault's was to have two iron bottles of as nearly as possible the same size cast in one piece. In one of these the substance was placed, and in the other a small quantity of mercury. The necks were then partially closed by loose stoppers, and the system was heated in a muffle. After heating it was withdrawn and allowed to cool, and the quantities remaining in the bottles were determined by suitable means.

* Grabowski, ${ }^{2}$ in 1866 , did much to shorten the Dumas calculation, while he allowed the method to retain all its accuracy and simplicity when he proposed to heat a bulb containing air in the same bath and of the same size as that containing the substance. After being heated the two bulbs were then sealed at the same temperature. Bunsen, ${ }^{3}$ in 1867 , employed an air-bath similar in principle to those of Mitscherlich and Regnanlt, but heated it by a very elaborate arrangement of gas-burners. $\mathrm{He}$ also simplified the calculation by taking care that all the tubes were of exactly the same weight and same size. He did not seal the tubes, but closed them by glass caps lined with indiarubber and fitted with glass plugs. Dumas, ${ }^{4}$ in cases where the vapour rendered the outlet difficult to seal, used globes fitted with ground stoppers.

For the Dumas processat high temperatures Deville and Troost, ${ }^{5}$ in $1857-9$, recommended heating the bulb in a specially constructed furnace in the vapours of substances having high but definite boiling-points, such as mercury, sulphur, zinc, or cadmium (in 1873 Dewar and Dittmar ${ }^{6}$ used a bath of boiling zinc in experiments on the vapour-density of potassium); for temperatures above the boiling-point of sulphur they used porcelain globes. For 7 temperatures up to that point the smaller and more compact apparatus devised by Greville Williams answers admirabiy.

Roscoe, ${ }^{8}$ last year, in determining the vapour densities of the chloride of lead and thallium, used porcelain globes of 300 c.c. capacity, heated in a muffle, but determined the temperature by the method of specific heat, a large piece of platinum being employed for the purpose, and checked the result by the simultaneous determination of the vapour-density of mercury.

For ${ }^{9}$ working at a reduced pressure Regnault proposed partially exhansting the bulb by means of an air-pump during the experiment; when the desired temperature was reached, it was sealed off at a point where the neck had been narrowed to a convenient size. In 1876 Habermann ${ }^{10}$ gave a complete diagram of the apparatus, replacing the air-pump by a Bunsen-pump; but although he made no alteration in the method, still it was referred to by Sommaruga 11 as Habermann's.

The readiest method of determining the residual air is that of Greville Williams, ${ }^{12}$ viz., to measure by means of a burette the quantity of mercury which is required to displace it. Deville and Troost ${ }^{13}$ recommended weighing the mercury required.

Various experiments had been performed on vapours mixed with air, but the main point in Playfair and Wanklyn's ${ }^{14}$ method ( $x 86 \mathrm{I}$ ) consisted in stopping the supply of vapour before the bath in which the bulb was being heated had attained its maximum temperature.

Natanson, ${ }^{25}$ in 1855 , in order to use the Gay-Lussac method up to a temperature of $300^{\circ}$, heated the upper part of the tube by means of charcoal in a cylindrical furnace, and determined the temperature by thermometers suspended in the air-space between the graduated tube and the inner tube of the heating apparatus. In correcting for the tension of mercury-vapour he used A vogadro's tables.

Greville Williams ${ }^{16}$ in 1857 , wishing to make some determinations at varying pressures, devised the following method:-The graduated tube is, after it has been filled and the bulb has been inserted, screwed by means of a nipple cemented to the bottom into an orifice in the top of a small metallic cistern into a second orifice in which a long open glass tube is fitted. Into this tube mercury is poured until the required pressure is obtained. To

${ }^{\prime}$ Ann. Chim. Phys. [3], 63, 53. ${ }^{2}$ Wien. Sitz. Ber. 53 [2], 92.

3 Liebig's Annn, I4r, 273 (1867); Phil. Mag., 34, I (1867).

5 Ibid. [3], 58, 257; "Watts' Dict. Chem,," 5, 373; Compt. Rend., 45,

$82 x ; 49,239$. Soy. Soc., 2I, $203(1873)$.

8 Deut. Chent. Ges. Ber., II, I196 (r878); Journ. Chemt. Soc., December, 1878, p. 937. 9 "Cours de Chim.," 4, 7x.

rI Liebig's Ann., 187, $34 \mathrm{I}(\mathrm{x} 877)$; Journ. Chem. Soc., 1877, vol. ii., 697 .

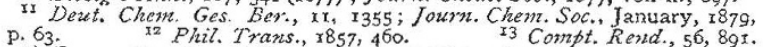

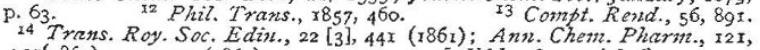
:01(1862); 122, $247(\times 862)$.

16 "Williams' Chem. Manip.," $542(1857)$. reduce the pressure the excess of mercury is allowed to escape by a tap in the side of the cistern. The whole is heated in a wateror oil-bath.

In Regnault's ${ }^{1}$ apparatus for the same purpose the two tubes are fastened to the bottom of the water-bath, and are connected by a T-piece, which is closed by a 3-way cock of special construction.

For determinations ${ }^{2}$ up to $150^{\circ}$ Greville Williams's compact modification consists in replacing the large vessel of mercury and the open glass cylinder by a cylinder closed and rounded at the lower extremity so as to resemble a large test-tube. This is then filled to a depth of 50-60 mm. with mercury, and above that with water or oil to a convenient height. The graduated tube is filled and the bulb inserted over the mercurial trough; it is then immersed in the large tube by means of a rod having at the end a small cup containing mercury. The large tube may be supported on wire gauze and heated by a Bunsen burner, or may be placed in a shallow oil-bath.

Schiffin, ${ }^{3}$ in 1862 , proposed steadying and manipulating the graduated tube by means of a loaded handle, which was secured to its upper extremity by spring clips.

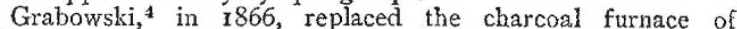
Natanson by a very much neater air-bath heated by gas, but the chief merit in his method is that a tube containing air is heated by the side of that containing the substance. As soon as the substance is all converted into vapour, air is passed up into the second tube until it occupies as nearly as possible the same volume as the vapour. After the operation the air is measured at atmospheric pressure and temperature.

Croullebois, ${ }^{5}$ in 1874 , reverted to Bineau's method of using a large globe with a long tube, but took the precaution to heat the upper portion in a water-bath. Deville, ${ }^{6}$ however, criticised his method rather severely, and pointed out that it was an unwieldy apparatus to manipulate.

In 1868 , Hofmann, ${ }^{7}$ in modifying the Gay-Lussac method, while he adopted the long tube which had been previously used by Bineau, Playfair, and Wanklyn, and Grabowski, introduces? such an important alteration into the apparatus that it is not spoken of as his modification, but as his method. Instead of heating the substance-tube by a water-, oil-, or air-bath, he simply inclosed it in a slightly larger mantle tube, and passed the vapour of a liquid of definite boiling-point through the intervening space, selecting the liquid according to the temperature required. By this means he not only rendered the apparatus much more compact, but he maintained a steady temperature with the greatest ease. Wichelhaus, ${ }^{8}$ in 1870 , anxious to avoid the uncertainty introduced by the doubt as to the temperature of the column of mercury between the bottom of the outer tube, and the trough, dispensed with the latter by fixing to the lower extremity of the substance-tube an inverted syphon containing mercury. Then by lengthening and suitably enlarging the lower extremity of the outer tube, the whole of the inner one can be surrounded by vapour.

Grabowski, ${ }^{9}$ in I 875 , in order to obtain a high temperature, employed the vapour of naphthalene as the heating medium ini using Hofmann's apparatus; but Engler, ${ }^{10}$ in the following year, finding that the stoppage of the tubes from the solidification of the condensed hydrocarbon was troublesome, proposed to obviate the difficulty in the following manner:-He fixed to the lower end of the onter tube a metal socket provided with a short sidetube similar to those used for heating funnels. Then, by boiling the heating medium in this tube and allowing the vapour to cohobate in the space between the two glass tubes, he dispensed with all the arrangement of flask, tubes, and condenser.

Hofmann, ${ }^{11}$ at the same time, made several modifications ins his apparatus : $\mathrm{r}$. He proposed heating the whole length of the inner tube by making the outer one long enough to enter the mercury in the trough, and provided for the escape of the condensed liquid and excess of steam by having a small side-tube affixed a short distance above the level of the mercury. $z$. Finding that graduated tubes were very liable to crack, he pro-

I Ann. Chim. Phys. [3], 63, 5x (x86r)

2 "Watts' Dict. Chem.," 5. 367 .

3 Fresenius Zeit. Anal. Chem., r, $32 \mathrm{r}$ (1862).

4 Wien. Sitz. Ber., $53[2], 92$ (1866).

5 Compt. Rend., 78,496 (1874); Joum. Chent. Soc., r2, N.S., 648 (1874).

6 Compt. Rend., $78,534 . \quad$ Dent. Chent. Ges. Ber., x, 198 (1864).

8 Ibid., 3, $166(\mathrm{r} 870)$; Journ. Chem. Soc., 1870,$324 ; 2877$, vol. i. 33

9 Deut. Chent. Ges. Ber., 8, $1437(1875)$

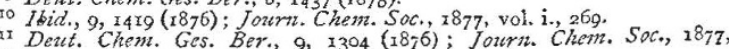
vol. i., 33 . 
posed using plain ones in the following manner:-In the bottom of the mercurial trough he placed a piece of sheet india-rubber attached to an iron plate, and provided with a groove on its upper surface; the iron plate was furnished with a handle. I) uring the heating the inner tube stood over the groove to allow of the escape of the mercury. When the level became stationary communication with the mercury in the trough was cut off by shifting the india-rubber disk until the inner tube rested on the flat surface. The height of the column in the inner tube was then noted by means of a cathetometer; the outer tube was then removed and a gummed label attached to the inner one to indicate the mercury level. After cooling, the volume of the vapour is determined from direct measurement. (3) In order to avoid the cracking of the tubes in cases where liquids of high boiling-point were used, he proposed connecting the lower end of the outer tube with the inner one by a cork through which two tubes leading to the flask or boiler passed. One of them led below the liquid, while the other, which was provided with a stop-cock, reached only just below the cork. If this stop-cock be closed while the liquid is being heated, a portion of it is forced up the space between the two glass tubes, and thus the mercurial column is heated more gradually. When the liquid reaches the boiling-point the stop-cock is opened, and the circulation of the steam proceeds as usual. The upper part of the outer tube must be sufficiently elongated or provided with a. small tube leading to a condenser.

Briilhl ${ }^{1}$ proposed working the Hofmann method at a very low pressure by employing a tube $\mathrm{I}^{\prime} 5$ metres long, with only a small quantity of substance, and was therefore able to make determinations at temperatures far below its boiling-point. He also made the following suggestions :-

I. In order to eliminate the troublesome element of the tension of mercury vapour (without using two tubes as Grabowski did), heat the column to the required temperature, note its height, then allow it to cool, introduce the substance and heat again to the same temperature till the height is constant. To cnsure uniformity of level in the bulb, keep it full to overflowing.

2. Before the first reading of the mercurial column a small piece of thin glass is passed up to liberate any air that may be contained in the mercury.

3. To make a mark on the tube a little above the vacuum mercury level and then only to calibrate about $150 \mathrm{~mm}$. down frow that point; then, to find the total volume, add the variable yolume below the mark to the fixed volume above the mark.

Muir and Suguira, ${ }^{2}$ in 1877 , finding that sometimes the weight of the inner tube caused the groove in the india-rubber disk to so far close as to prevent the escape of the mercury while heating the substance, used a plain india-rubber disk which was fastened to the bottom of the trough, a disk of cork intervening. Communication between the mercury in the tube, and that in the trough was maintained by means of a short piece of glass tubing bent at right angles. A second tube long enough to stand silightly above the level of the mercury in the trough served to carry off, from the space between the two tubes, the condensed liquid and excess of vapourr. They adopted Hofmann's original method of passing the steam in at the top of the outer tube, but used a small tube passing through a perforated cork in preference to one fused to the end.

Brühl ${ }^{3}$ has, this year, proved by most carefully conducted experiments that the Hofmann method cannot be used above $220^{\circ}$ owing to the great and rapidly increasing vapour-tension of mercury, but has omitted the grave objection to his own method. Playfair and Wanklyn ${ }^{4}$ called attention, in $186 \mathrm{r}$, to the fact that Bineau, ${ }^{5}$ in 1846 , pointed out that in vapour-density methods at very reduced pressures slight errors in the readings of the mercurial level introduce very serious errors into the result ; this remark also applies to Croullebois.

In the overflow methods, which are in reality modifications of the Gay-Lussac, seeing that they are performed with known weights of substance, the first name is Hofmann, ${ }^{6}$ who, in 1860 , gave a very meagre description of his apparatus, when he wrote that he used a U-tube heated in a paraffin bath, and estimated

${ }^{\prime}$ Deut. Chem. Ges. Ber., 9, $1368(1876)$; Fourn. Chent. Soc., 1877 , vol. i.,

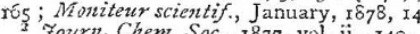

3 Deut. Chem. Ges. Ber., 12, 197 (1879); Fourn. Chem. Soc., 1879, abst., 499 .

4 Trans. Roy. Soc. Editu, 22 [3], 44 r (286r).

.5 Phil. Trans., 150, 414 (1860); Ann. Chem. Pharm., Supp., I, 10 (186r). the volume of the vapour by the mercury expelled. Wertheim, 1 in $1862-64$, in his papers on Coniin, gave very full details of method, in which he used two tubes suspended side by side in a flask.

Watts, ${ }^{2}$ in $\mathbf{1} 867$, employed a globe with a ground neck, into which an outlet-tube reaching nearly to the bottom of the globe was accurately fitted. The globe being filled with mercury and the substance introduced, the quantity of mercury expelled on heating served as a basis for calculating the volume occupied by the vapour. Victor Mayer, ${ }^{3}$ in 1876 , introduced two very important alterations, he avoided the vapour-tension of mercury by using fusible metal and placed the outlet at the bottom of the bulb. His experiments at that time were all made in the vapour of boiling sulphur, but Graebe, ${ }^{4}$ last year, wishing to employ a higher temperature, used phosphorus pentasulphide, which boils at $530^{\circ}$.

Frerichs, ${ }^{5}$ in 1876 , used mercury in an apparatus similar in principle to that of Watts's, but employed an inverted flask, and bronght the exit-tube, which was furnished with an inverted syphon, through a suitable outlet in the bottom of the bath.

Goldschmiedt and Ciamician, ${ }^{6}$ in 1877 , used mercury with the simpler bulb of Victor Meyer, but added a small side-tube to the outlet, so that the mercury expelled could be weighed from time to time during the heating. Victor Meyer, ${ }^{7}$ in the same year, modified the shape of the bulb, but heated it in a tube similar to that employed by Greville Williams in Gay-Lussac's determinations, but of sufficient length for the upper part of the tube to serve as condenser.

Pfaundler's method, ${ }^{8}$ of which a preliminary notice appeared in 1870 , but which was not brought prominently forward till this year, is based on the increased tension of the air in an elongated bulb produced by heating after the introduction of the substance as compared with a similar determination on air in a bulb of the same size. A very short description appeared in 1874 of a method devised by Dulong ${ }^{9}$ which is based on the same principle.

Last year Hofmann ${ }^{10}$ proposed two methods; in one of these he heated the weighed substance over mercury in the closed limb of a U-tube, and marked the level of the mercury in the open limb by sliding a pointed tube through a loosely fitting perforated cork until it touched the surface. When the apparatus was cool; the volume of the vapour was calculated from the weight of mercury required to restore the level to that same point. The other consisted in introducing into a tube a small but weighed quantity of substance, then exhausting it and sealing it, and heating in a jacketed tube. At the required temperature the point of the glass tube is opened to allow air to enter, and then at once sealed again. After cooling, the point is opened under mercury or water, and the volume occupied by the vapour is measured.

In Meyer's ${ }^{11}$ method, which is so recent and well-known as not to require any explanation, the principle is that of Pfaundler's, but by having the neck elongated and the outlet as a side-tube, the substance is introduced after the bulb is heated to the required temperature, and by allowing the air expelled by the vapour free egress into a graduated tube, it can be measured under atmospheric conditions. It is, therefore, so simple that the operation only requires a very short time from first to last.

Dewar and Scott ${ }^{12}$ have lately determined the vapour-densities of potassium and sodium in a modified form of Meyer's apparatus.

In this sketch I have purposely kept off the very enticing ground of formulce, as they of themselves open up so wide a field that they could not be dove-tailed into the history of the subject, which from any point of view is interesting.

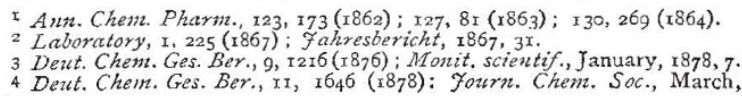

1879,260 .

6 Deut. Chem. Ges. Ber., 10, 641 (1877); Monit. scientif., January,

${ }_{2} 878, x_{3}$.

7 Deut. Chem. Ges. Ber., 10, $2068(1877)$.
8 Ibid., 3, 825 (1870); 12, $165(1879)$; foum. Chem. Soc., $x 879$, abst.,

499. Compt. Rend., 78, 536 1874)); fourn. Chem. Soc., 12, N.S. 650 $\left(\begin{array}{rl}8 \\ 10\end{array} 4\right)$.

Chem. Ges. Ber., II, 1694 (1878); Fourn. Chem. Soc., March, I879, I96.

${ }_{12}$ Deut. Chem. Ges. Ber., II, I867 (1878); Ix, 2253 (1878); Chemicat Nezus, February 14, 1879; Deut. Chem. Ges. Ber., I2, 609 (1879); 12, 1112 $(1879)$

${ }_{12}$ Proc Roy. Soc., 29, 206 (1879). 